\title{
Efficiency Optimization of the High-Power Isolated DC/DC Converters through THD and Losses Reduction in Isolation Transformers
}

\author{
D. Vinnikov ${ }^{1}$, V. Bolgov ${ }^{2}$ \\ ${ }^{1}$ Department of Electrical Drives and Power Electronics, Tallinn University of Technology \\ Ehitajate tee 5, 19086 Tallinn (Estonia) \\ Phone number:+372 6203705, fax number:+372 6203701, e-mail: dm.vin@mail.ee \\ ${ }^{2}$ Department of Electrical Engineering and Electrical Machines, Tallinn University of Technology \\ Ehitajate tee 5, 19086 Tallinn (Estonia) \\ Phone/Fax number:+372 6203800, e-mail: victor_bolgov@yahoo.com
}

\begin{abstract}
This paper describes a method of improving efficiency of the high-power transformer-isolated DC/DC converters by means of proper selection of an inverter switch duty cycle. The paper revises old suggestions and recommendations for choosing the maximal duty cycle value on the basis of physical limits imposed by new solid-state devices. The resulting improved efficiency of the converter is described considering losses in separate energy conversion stages.
\end{abstract}

\section{Keywords}

DC/DC converters, efficiency, isolation transformer, inverter.

\section{Introduction}

High-power transformer-isolated DC/DC converters have a wide scope of applications. The most challenging area is the rolling stock, where the $\mathrm{DC} / \mathrm{DC}$ converter topologies are mostly used in auxiliary power supplies (APS). In general, APS is the power interface between the traction catenary and the vehicle onboard low-voltage consumers. The auxiliary power supply is directly connected to the traction catenary, which means that it must be fully compliant with specific catenary properties; the large supply voltage swing being one of those. The continuous failure-free operation of the APS must be guaranteed within the following limits of the supply voltage (in DC traction systems):

$$
0.67 U_{i n, n o m} \leq U_{i n} \leq 1.3 U_{i n, n o m}
$$

where $U_{\text {in,nom }}$ is the standardized nominal value of the traction catenary. Table I provides the visual evaluation of the lower and upper limits of different traction catenaries specified by the standard EN50163 [1].
TABLE I. - Standardized Catenary Voltage Fluctuations

\begin{tabular}{|c|c|c|}
\hline $\begin{array}{c}\text { NOMINAL } \\
\text { VOLTAGE } \\
U_{\text {in,nom }}\end{array}$ & $\begin{array}{c}\text { CONTINUOUS } \\
\text { MINIMAL } \\
\text { VOLTAGE } U_{\text {in, } \min }\end{array}$ & $\begin{array}{c}\text { CONTINUOUS } \\
\text { MAXIMAL } \\
\text { VOLTAGE } U_{\text {in, } \max }\end{array}$ \\
\hline 600 & 400 & 770 \\
\hline 750 & 500 & 950 \\
\hline 1500 & 1000 & 1950 \\
\hline 3000 & 2000 & 3900 \\
\hline
\end{tabular}

In the rolling stock applications, the output voltage at the rated load should not change over the full range of the input voltage fluctuations. Based on the accepted voltage fluctuations (Table I), the line regulation (LR) requirement for the rolling stock APS supplied from the traction catenary can be formulated as follows:

$$
L R(\%)=\frac{U_{O(\operatorname{Uin}, \max )}-U_{O(\operatorname{Uin}, \min )}}{U_{O(\operatorname{Uin}, n o m)}} \cdot 100 \%=0 \%
$$

where $U_{O}$ is the output voltage of the converter. Thus, zero-percent line regulation must be considered in the designing and dimensioning of the APS converter for the rolling stock [2].

\section{Inverter-Transformer Assembly: Design and Operation}

The main specific feature of the APS for the rolling stock is that its input and output stages need to be galvanically isolated. The requirement for safety isolation depends on the integrity of the interconnections between the output of the power supply and the safety isolation provided by the load. Reference should be made to the European standards EN60950 and EN50155. In view of these requirements, a simplified block-diagram of a typical DC/DC auxiliary converter for the DC-fed rolling stock can be proposed (Fig. 1). 


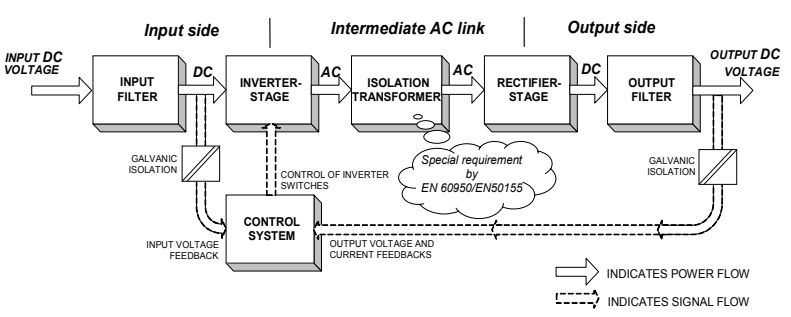

Fig. 1. The required structure of the onboard APS converter for the DC-fed rolling stock

The isolation transformer and the zero-percent line regulation required are the main challenges for the designer. Such multistage energy transfer (Fig. 1) is always associated with high losses and lack of efficiency of the developed converter. The most emphasized part here is the inverter-transformer assembly: its operation must be precisely coordinated to achieve higher efficiency and flexibility of the whole converter.

For the described application, the half- and full-bridge isolated $\mathrm{DC} / \mathrm{DC}$ converter topologies are most feasible: despite relative simplicity, they can provide galvanically isolated output voltage with good regulation properties and with reduced voltage stress on the primary switching devices. This research mostly covers the half-bridge topology based the APS converter (Fig. 2) developed for the $3 \mathrm{kV}$ DC rolling stock [3]. General specifications are presented in Table II.

TABLE II. - Technical Specifications of the Experimental Converter

\begin{tabular}{|l|c|}
\hline \multicolumn{2}{|c|}{ INVERTER STAGE } \\
\hline $\begin{array}{l}\text { Continuous minimal input voltage } U_{\text {in,min }}, \\
\text { VDC }\end{array}$ & 2000 \\
\hline $\begin{array}{l}\text { Continuous maximal input voltage } U_{\text {in,max }}, \\
\text { VDC }\end{array}$ & 3900 \\
\hline Nominal input voltage $U_{\text {in,nom }}$, VDC & 3000 \\
\hline Switching frequency $f_{\text {sw }}, \mathrm{kHz}$ & 1 \\
\hline \multicolumn{2}{|c|}{ ISOLATION TRANSFORMER STAGE } \\
Type of semiconductor switches & $\begin{array}{c}\text { Infineon } \\
\text { IGBT }\end{array}$ \\
\hline \multicolumn{2}{|c|}{ Gammamet } \\
toroidal core \\
Core type of an isolation transformer & 0.6 \\
\hline Operating flux density $B_{m}, \mathrm{~T}$ & 70 \\
\hline Ambient temperature $T_{\text {amb }},{ }^{\circ} \mathrm{C}$ & 50 \\
\hline Temperature rise $\Delta T,{ }^{\circ} \mathrm{C}$ & PURALIT ${ }^{\circledR}$ litz \\
\hline Wiring material & 350 \\
\hline \multicolumn{2}{|c|}{ MISLANEOUS } \\
\hline Converter output voltage $U_{O}$, VDC \\
\hline Desired output power $P_{O}, \mathrm{~kW}$ \\
\hline
\end{tabular}

The idea of the control of half-bridge converter operating under the large input voltage swing is to maintain the constant volt-seconds applied to the transformer primary winding (Fig. 3). In other words, the relation $U_{i n} D$ (where $U_{i n}$ is the input voltage and $D=t_{o n} / T_{s w}$ is the transistor duty cycle) should be constant in all the operating points of the converter [4]. To compensate the input voltage variation, the duty cycle of the inverter switch should change inversely proportional to $U_{i n}$ to maintain a constant output voltage, $U_{O}$ :

$$
U_{\text {out }}=\frac{U_{\text {in }} \cdot D}{n},
$$

where $n$ is the turns ratio of the isolation transformer (power losses have been neglected). To achieve a good design, the operation of the inverter-transformer assembly should be investigated and analyzed in two most demanding operating points: at minimum input voltage, where the switch duty cycle is approaching its predefined maximum $D_{\max }$ and at maximum input voltage, where the duty cycle becomes minimal $\left(D_{\min }\right)$. These two operating points could be set as boundary operating points. The duty cycle variation range of any isolated $\mathrm{DC} / \mathrm{DC}$ converter with a large input voltage swing is always lying between these two boundaries. Another important operating point is the nominal operating point, which corresponds to the nominal operating voltage and could be used for the estimation of the efficiency of the power converter.

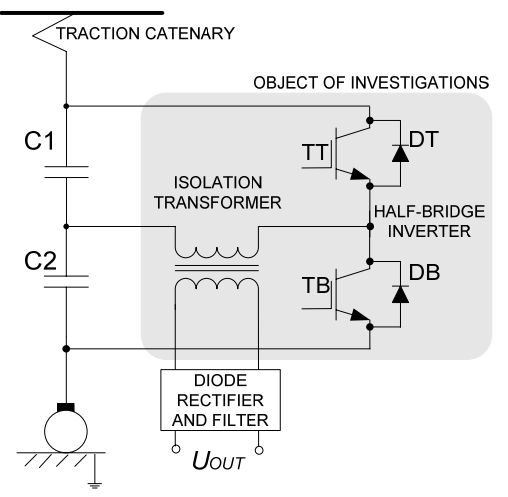

Fig. 2. Simplified scheme of the experimental converter. The required structure of the onboard APS converter for the DC-fed rolling stock

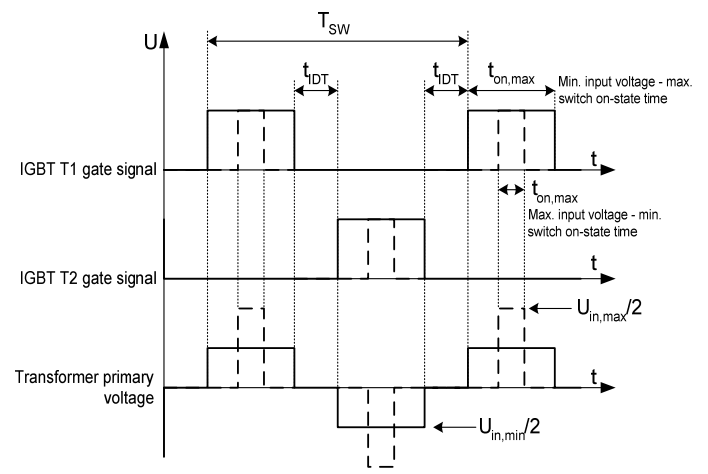

Fig. 3. Timing diagrams of the inverter-transformer assembly of the half-bridge DC/DC converter

At a fixed switching frequency and with normal steadystate operation, the volt-seconds applied to the transformer windings are constant, independent of the input voltage and load current:

$$
U_{i n} \cdot t_{o n}=\frac{U_{i n} \cdot D}{f_{s w}}=\frac{n \cdot U_{O}}{f_{s w}},
$$


where $U_{\text {in }}$ is the input voltage, $t_{\text {on }}$ is the switch on-state time, $D$ is the switch duty cycle, $U_{O}$ is the output voltage, $n$ is the isolation transformer turns ratio, and $f_{s w}$ is the switching frequency.

\section{Selection of the Duty Cycle Variation Range}

The selection procedure of the duty cycle variation range should always begin from the definition of the maximum switch duty cycle corresponding to the minimal input voltage. According to conservative design practice for the full- and half-bridge converters, several unified values of the maximum switch duty cycle, such as $D_{\max }=0.45$ [5] or even $D_{\max }=0.4$, are used [4]. This is done mostly to provide a proper safety margin, thus preventing a short circuit across the supply voltage, which can cause the destruction of power transistors. The minimum duty cycle value $D_{\min }$ in power converters with the large input voltage swing is generally selected using (5).

$$
D_{\text {min }}=\frac{U_{i n, \text { min }}}{U_{i n, \text { max }}} \cdot D_{\text {max }} \cdot
$$

The conservative selection procedure of the duty cycle based on predefined $D_{\max }$ values is not always useful because it limits the flexibility and even can reduce the efficiency of the inverter-transformer assembly. The selection of $D_{\max }$ should be individually performed in respect to the specific properties of the converter, such as converter topology, application field, transistor types, isolation transformer specifications, etc. This results in the influence on the dynamic properties of switching transistors.

\section{An idea - shifting of $D_{\max }$ towards its absolute maximum}

To improve the efficiency and flexibility of the highpower half- and full-bridge isolated DC/DC converters, the authors propose to shift the maximum switch duty cycle $D_{\max }$ towards its absolute maximum as close as possible.

Theoretically, in the investigated transformer-isolated half-bridge DC/DC converter, the absolute maximum duty cycle can approach 0.5 (switch on-state time $t_{\text {on, lim }}$ is half the switching period $T_{s w}$ ) but in practice it is always limited by some certain value $D_{\text {lim }}$, which can be expressed as

$$
D_{\lim }=\frac{t_{o n, \lim }-t_{I D T}}{T_{s w}}
$$

where $t_{I D T}$ is the interlock delay time between switching on and off the opposite arm transistors to prevent cross conduction followed by the short circuit of the DC-link and damage of power transistors. To calculate the interlock delay time, the following equation could be used:

$$
t_{I D T}=\left[\begin{array}{l}
\left(t_{d_{-} \text {off }, \text { max }}-t_{d_{-} \text {on, } \min }\right)+\left(t_{f, \text { max }}-t_{r, \text { min }}\right)+ \\
+\left(t_{P D D, \text { max }}-t_{P D D, \text { min }}\right)
\end{array}\right] \cdot S F,(7)
$$

where $t_{d \text {-off,max }}$ and $t_{d-o n \text {, min }}$ are the maximal turn-off and minimal turn-on delay times of the switching transistor, respectively; $t_{f, \max }$ and $t_{r, \min }$ are the maximal fall time and minimal rise time of the switching transistor; $t_{P D D, \max }$ and $t_{P D D, \min }$ are the maximal and minimal signal propagation delays from the control microprocessor to the switching transistor and $S F$ is the safety factor. In (6) the first four terms describe the characteristics of the switching transistor itself plus the gate resistor that is used. The last two terms are the propagation delay time difference determined by the control signal propagation chain from the control circuitry via the gate driver to the switching transistor. Often the interlock delay time is calculated from typical datasheet values just multiplying by the safety factor from field experience. For instance, [6] proposes to use the safety factor $S F=1.2$. The discussed experimental device is based on $6.5 \mathrm{kV} 200 \mathrm{~A}$ IGBTs FZ200R65KF1 with dedicated drivers controlled via fiber optics from a high-performance microcontroller, the interlock delay time will be about $t_{I D T}=9 \mathrm{us}$, resulting in the absolute maximum duty cycle $D_{l i m}=0.49$ at the switching frequency $f_{s w}=1 \mathrm{kHz}$.

Evidently, such procedure demands special accuracy in ensuring correct IDT, which must be done for each application in particular. Thus, in the discussed application with $t_{I D T}=9$ us the proposed maximum switch duty cycle will be $D_{\max }=D_{\text {lim }}=0.49$. The selection of the minimum duty cycle value $D_{\min }$ should be done by (5).

\section{Impact of Different Duty Cycle Variation Ranges on the Efficiency of the Inverter- Transformer Assembly}

To verify how the selection of the duty cycle variation range can affect the efficiency of the inverter-transformer assembly of the high-voltage IGBT-based half-bridge DC/DC converter, a series of experiments were performed. The duty cycle variation range was calculated in accordance with the input voltage boundaries presented in Table II. The first two ranges $A$ and $B$ were selected upon the standard procedure with earlier discussed unified maximum duty cycle values 0.4 and 0.45 , correspondingly. The selection of the third duty cycle variation range $C$ was based on the proposed design improvement procedure. The investigated duty cycle variation ranges are presented in Table III.

TABLE III. - Duty Cycle Variation Ranges Used in the Analysis

\begin{tabular}{|c|c|c|c|}
\hline $\begin{array}{c}\text { CASE } \\
\text { STUDY }\end{array}$ & $\begin{array}{c}D_{\max } \\
\left(U_{\text {in, } \max }=\right. \\
2000 \mathrm{~V})\end{array}$ & $\begin{array}{c}D_{\text {nom }} \\
\left(U_{\text {in, nom }}=\right. \\
3000 \mathrm{~V})\end{array}$ & $\begin{array}{c}D_{\min } \\
\left(U_{\text {in, } \max }=\right. \\
3900 \mathrm{~V})\end{array}$ \\
\hline $\mathrm{A}$ & 0.4 & 0.27 & 0.21 \\
\hline $\mathrm{B}$ & 0.45 & 0.3 & 0.23 \\
\hline $\mathrm{C}$ & 0.49 & 0.33 & 0.25 \\
\hline
\end{tabular}


Further, the efficiency of the half-bridge inverter and the isolation transformer will be analyzed and compared for these three operating points with similar conditions (see Table I for details).

\section{A. Operation Conditions and Losses of a Half-Bridge Inverter}

With the duty cycle being shifted towards maximum, the rms voltage applied to the transformer's primary winding will be increased due to the longer conduction time of the IGBT. For the same transferred power, the rms value of the primary current should proportionally decrease. As a consequence, the rms current of the switching transistors will be decreased, thus having a positive influence on the inverter losses. The comparison of the rms currents of the switching transistor for the different operating voltages and duty cycle values is presented in Table IV.

TABLE IV. - Impact of the Duty Cycle Variation Range on the Operating Values of the Inverter Switches

\begin{tabular}{|l|c|c|c|}
\hline $\begin{array}{l}\text { OPERATING } \\
\text { POINT }\end{array}$ & $\begin{array}{c}U_{i n, \min } \\
(2000 \mathrm{~V})\end{array}$ & $\begin{array}{c}U_{i n, n o m} \\
(3000 \mathrm{~V})\end{array}$ & $\begin{array}{c}U_{i n, \max } \\
(3900 \mathrm{~V})\end{array}$ \\
\hline \multicolumn{4}{|c|}{ CASE STUDY A } \\
\hline Switch duty cycle $D$ & 0.4 & 0.27 & 0.21 \\
\hline $\begin{array}{l}\text { Switch average } \\
\text { current, } I_{c, a v}(\mathrm{~A})\end{array}$ & 25 & 16.7 & 12.8 \\
\hline $\begin{array}{l}\text { Switch rms current, } \\
I_{c, r m s} \text { (A) }\end{array}$ & 39.5 & 32.1 & 28.0 \\
\hline \multicolumn{4}{|c|}{ CASE STUDY B } \\
\hline Switch duty cycle $D$ & 0.45 & 0.3 & 0.23 \\
\hline $\begin{array}{l}\text { Switch average } \\
\text { current, } I_{c, a v} \text { (A) }\end{array}$ & 25 & 16.7 & 12.8 \\
\hline $\begin{array}{l}\text { Switch rms current, } \\
I_{c, r m s} \text { (A) }\end{array}$ & 37.3 & 30.4 & 26.7 \\
\hline \multicolumn{4}{|c|}{ CASE STUDY C } \\
\hline Switch duty cycle $D$ & 0.49 & 0.33 & 0.25 \\
\hline $\begin{array}{l}\text { Switch average } \\
\text { current, } I_{c, a v} \text { (A) }\end{array}$ & 25 & 16.7 & 12.8 \\
\hline $\begin{array}{l}\text { Switch rms current, } \\
I_{c, r m s} \text { (A) }\end{array}$ & 35.7 & 29.0 & 25.6 \\
\hline
\end{tabular}

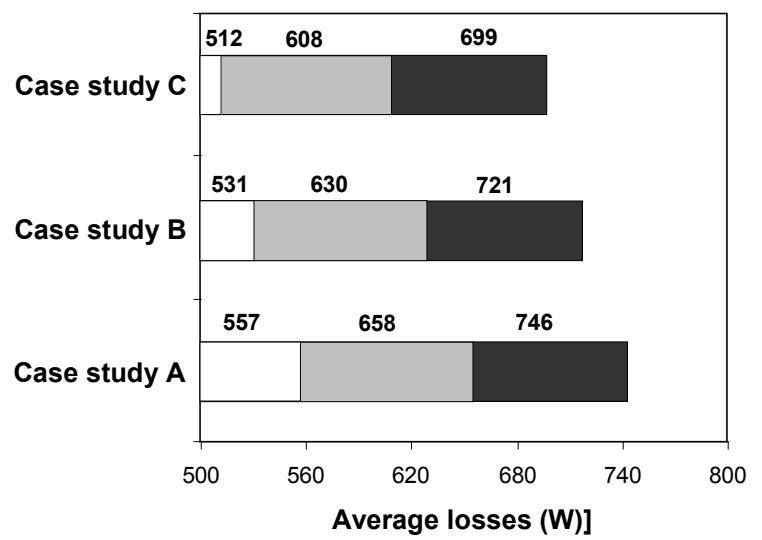

$\square$ Maximal input voltage - minimum duty cycle: $U_{\text {in, } \max } D_{\min }$ $\square$ Nomimal input voltage - nominal duty cycle: $U_{i n, n o m} D_{n o m}$

Minimal input voltage - maximum duty cycle: $U_{i n, \min } D_{\max }$

Fig. 4. Average losses of half-bridge inverter operating with different switch duty cycles and input voltages
The analysis (Fig. 4) shows that on an increase of the switch duty cycle at the maximal input voltage by $22.5 \%$, the total losses of the half-bridge inverter could be reduced by $8.1 \%$. The proportional increase of the duty cycle insures a $7.5 \%$ and $6.3 \%$ loss reduction at the nominal and minimal input voltages, respectively. Although the presented loss reduction increases the efficiency of the inverter only by some fractions of percent, the cooling effort could be reduced, thus resulting in a more space-saving design.

\section{B. Operation Conditions and Efficiency of the Isolation Transformer}

The shifting of $D_{\max }$ towards its absolute maximum will be followed by the decrease of the amplitude value of the transformer secondary voltage. Neglecting losses in the rectifier diodes and output filter components, the transformer secondary amplitude voltage could be estimated by (8).

$$
U_{\text {sec }, a m p}=\frac{U_{O}}{2 \cdot D}
$$

where $U_{O}$ is the converter output voltage. Table $\mathrm{V}$ shows the impact of the duty cycle variation range change on the main specifications of the isolation transformer.

It is obvious that due to shifting of $D_{\max }$ towards its absolute maximum, the turns number of the transformer will also change. Due to an increased duty cycle, the amplitude value of the transformer secondary voltage will be reduced, thus decreasing voltage stress on the rectifier diodes. During the analysis it was assumed that the general specifications of the isolation transformer (core type, volume, operating flux density, ambient temperature and temperature rise, cross-section and type of winding wires, etc. as well as input voltage swing and operating frequency) remain the same for all the investigated cases (see Table I).

Further, based on the data presented in Tables I and V, three different isolation transformers were evaluated and compared for the whole operation range in terms of losses and efficiency. Cases $A, B$ and $C$ correspond to the transformers designed to operate at $D_{\max }$ values of 0.4 , 0.45 and 0.49 , respectively. Each transformer operation was analyzed in three operating points - at $U_{\text {min }}, U_{\text {nom }}$ and $U_{\min }$ with the corresponding $D_{\min }, D_{\text {nom }}$ and $D_{\max }$. The comparison between cases $A, B$ and $C$ at those operating points is demonstrated below in Figs. 8-12.

It should be mentioned that due to duty cycle changes, to match the input voltage, the converter assembly encounters variable harmonic content. The square wave pulses (Fig. 1) used in the DC/DC converter can be presented as a fundamental component and a set of higher harmonic components by applying the Fourier transformation

$$
u(t)=\frac{4 \cdot U_{p r, a m p}}{\pi} \sum_{n=1,3,5}^{\infty} \frac{1}{N_{n}} \sin N_{n} D \pi \cdot \cos N_{n} \omega t,
$$


where $U_{p r, a m p}$ is the amplitude value of the square wave primary voltage of the isolation transformer and $D$ is the inverter switch duty cycle corresponding to the voltage.

TABLE V. - Impact of the Duty Cycle Variation Range on the Specifications of the Isolation Transformer

\begin{tabular}{|c|c|c|c|}
\hline $\begin{array}{l}\text { OPERATING } \\
\text { POINT }\end{array}$ & $\begin{array}{c}U_{i n, \min } \\
(2000 \mathrm{~V})\end{array}$ & $\begin{array}{c}U_{\text {in,nom }} \\
(3000 \mathrm{~V})\end{array}$ & $\begin{array}{c}U_{\text {in, } \max } \\
(3900 \mathrm{~V})\end{array}$ \\
\hline \multicolumn{4}{|c|}{ CASE STUDY A } \\
\hline Switch duty cycle $D$ & 0.4 & 0.27 & 0.21 \\
\hline $\begin{array}{l}\text { Primary amplitude } \\
\text { voltage } U_{p r, a m p}(\mathrm{~V})\end{array}$ & 1000 & 1500 & 1950 \\
\hline $\begin{array}{l}\text { Primary rms voltage } \\
U_{p r, r m s}(\mathrm{~V})\end{array}$ & 894.4 & 1102 & 1264 \\
\hline $\begin{array}{l}\text { Primary rms current } \\
I_{p r, r m s}(\mathrm{~A})\end{array}$ & 55.9 & 45.4 & 39.6 \\
\hline $\begin{array}{l}\text { Second. amplitude } \\
\text { voltage } U_{\text {sec,amp }}(\mathrm{V})\end{array}$ & 437.5 & 648.2 & 833.3 \\
\hline $\begin{array}{l}\text { Secondary rms } \\
\text { voltage } U_{\text {sec,rms }}(\mathrm{V})\end{array}$ & 390.6 & 481.2 & 551.9 \\
\hline $\begin{array}{l}\text { Secondary rms } \\
\text { current } I_{s e c, r m s}(\mathrm{~A})\end{array}$ & 128 & 103.9 & 90.7 \\
\hline Turns ratio & \multicolumn{3}{|c|}{2.29} \\
\hline Primary turns & \multicolumn{3}{|c|}{41} \\
\hline Secondary turns & \multicolumn{3}{|c|}{18} \\
\hline \multicolumn{4}{|c|}{ CASE STUDY B } \\
\hline Switch duty cycle $D$ & 0.45 & 0.3 & 0.23 \\
\hline $\begin{array}{l}\text { Primary amplitude } \\
\text { voltage } U_{p r, a m p}(\mathrm{~V})\end{array}$ & 1000 & 1500 & 1950 \\
\hline $\begin{array}{l}\text { Primary rms voltage } \\
U_{p r, r m s}(\mathrm{~V})\end{array}$ & 948.7 & 1162 & 1323 \\
\hline $\begin{array}{l}\text { Primary rms current } \\
I_{p r, r m s}(\mathrm{~A})\end{array}$ & 52.7 & 43 & 37.8 \\
\hline $\begin{array}{l}\text { Second. amplitude } \\
\text { voltage } U_{\text {sec,amp }}(\mathrm{V})\end{array}$ & 388.9 & 583.3 & 760.9 \\
\hline $\begin{array}{l}\text { Secondary rms } \\
\text { voltage } U_{\text {sec,rms }}(\mathrm{V})\end{array}$ & 369.1 & 452.1 & 514.8 \\
\hline $\begin{array}{l}\text { Secondary rms } \\
\text { current } I_{\text {sec, } r m s}(\mathrm{~A})\end{array}$ & 135.5 & 110.5 & 97.1 \\
\hline Turns ratio & \multicolumn{3}{|c|}{2.57} \\
\hline Primary turns & \multicolumn{3}{|c|}{42} \\
\hline Secondary turns & \multicolumn{3}{|c|}{16} \\
\hline \multicolumn{4}{|c|}{ CASE STUDY C } \\
\hline Switch duty cycle $D$ & 0.49 & 0.33 & 0.25 \\
\hline $\begin{array}{l}\text { Primary amplitude } \\
\text { voltage } U_{p r, a m p}(\mathrm{~V})\end{array}$ & 1000 & 1500 & 1950 \\
\hline $\begin{array}{l}\text { Primary rms voltage } \\
U_{p r, r m s}(\mathrm{~V})\end{array}$ & 990 & 1219 & 1379 \\
\hline $\begin{array}{l}\text { Primary rms current } \\
I_{p r, r m s}(\mathrm{~A})\end{array}$ & 50.5 & 41 & 36.3 \\
\hline $\begin{array}{l}\text { Second. amplitude } \\
\text { voltage } U_{\text {sec,amp }}(\mathrm{V})\end{array}$ & 357.1 & 535.7 & 696.4 \\
\hline $\begin{array}{l}\text { Secondary rms } \\
\text { voltage } U_{\text {sec,rms }}(\mathrm{V})\end{array}$ & 353.6 & 345.4 & 492.5 \\
\hline $\begin{array}{l}\text { Secondary rms } \\
\text { current } I_{\text {sec,rms }} \text { (A) }\end{array}$ & 141.4 & 114.8 & 101.6 \\
\hline Turns ratio & \multicolumn{3}{|c|}{2.8} \\
\hline Primary turns & \multicolumn{3}{|c|}{42} \\
\hline Secondary turns & \multicolumn{3}{|c|}{15} \\
\hline
\end{tabular}

Assuming a lossless converter with a purely resistive load, we can consider the secondary voltage, the primary and secondary current and the primary and secondary powers to be of the same harmonic content. Then the total harmonic distortion (THD) could be defined as the ratio of the sum of the powers of all harmonic components to the power of the fundamental harmonic:

$$
T H D=\frac{\sum_{n=1,3,5}^{\infty} P_{n}}{P_{1}} .
$$

In the considered cases, equations (9) and (10) take into account odd harmonics up to 49th order.

Fig. 5 shows the dependence of THD on the duty cycle, estimated for the full duty cycle variation range theoretically available for the half-bridge inverter. This figure helps us to understand the plot presented in Fig. 6. The latter shows the transformer power at the fundamental and higher harmonics. As can be seen, at different operating points, the relationship between the powers transferred at the fundamental and higher frequencies can vary according to the changes in THD.

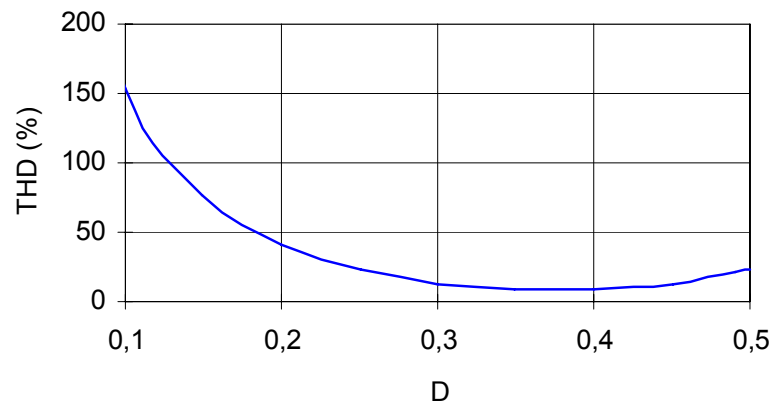

Fig. 5. THD as a function of inverter switch duty cycle

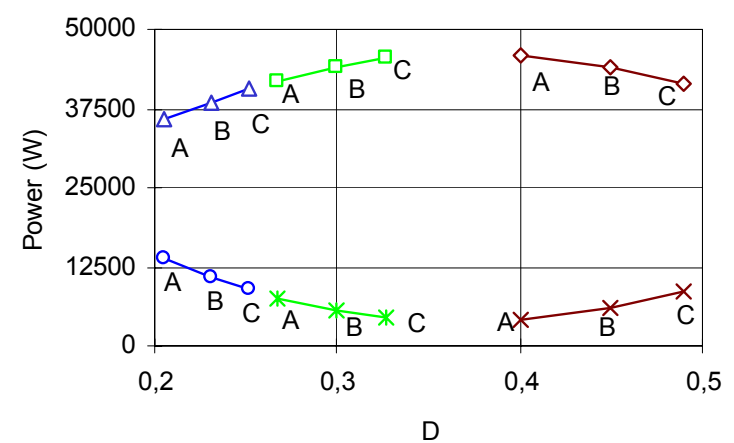

$\neg-$ Pow er at fundamental frequency, operating point Umax, Dmin

$-\square \_$Pow er at fundamental frequency, operating point Unom, Dnom $\checkmark$ Pow er at fundamental frequency, operating point Umin, Dmax * Pow er at higher frequencies, operating point Unom, Dnom $\star \leftarrow$ Pow er at higher frequencies, operating point Umin, Dmax

Fig. 6. Power transferred through isolation transformer at the fundamental and higher frequencies in case studies $A, B$ and $C$, respectively

Fig. 7 demonstrates the total losses of the three transformers split into losses at the fundamental and higher frequencies. As can be seen, the total power losses decrease at any voltage if an isolation transformer is designed to operate with a higher maximal duty cycle 
value. The fundamental losses can increase or decrease depending on the fundamental component of the power at the chosen duty cycle. But the power losses at higher frequencies always decrease even at minimal operational voltage and maximal duty cycle value while the higher maximal duty cycle value is being chosen to design a DC/DC converter.

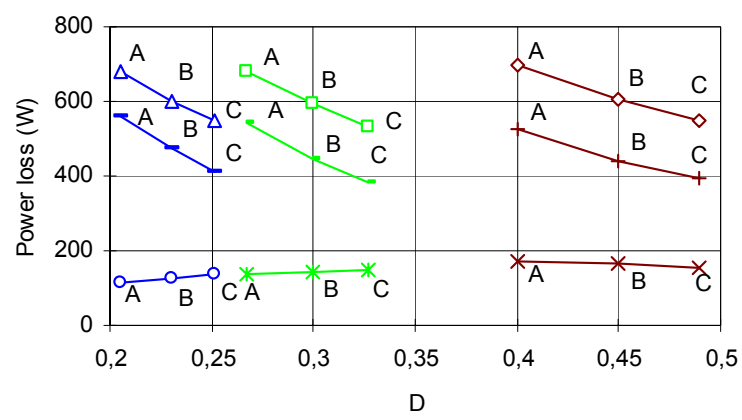

$\neg-$ Total pow er losses, operating point Umax, Dmin

—— Total pow er losses, operating point Unom, Dnom

$\smile$ Total pow er losses, operating point Umin, Dmax

- $\ldots$ Pow er losses at fundamental frequency, operating point Umax,

Dowin Dnom

$\rightarrow$ Pow er losses at fundamental frequency, operating point Umin Dmax

__ Pow er losses at higher frequency, operating point Umax, Dmin

_- Pow er losses at higher frequency, operating point Unom, Dnom

— Pow er losses at higher frequency, operating point Umin, Dmax

Fig. 7. Power losses in an isolation transformer: total, at the fundamental and higher frequencies in case studies $A, B$ and $C$, respectively

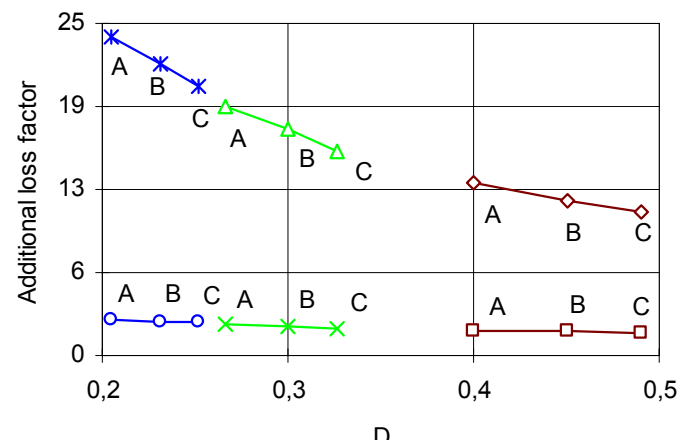

* Additional loss factor for primary w inding, operating point Umax, Dmin

$\neg-$ Additional loss factor for primary w inding, operating point Unom, Dnom

$\prec$ Additional loss factor for primary winding, operating point Umin, Dmax

—_ Additional loss factor for secondary w inding, operating point Umax, Dmin

$x$ Additional loss factor for secondary $w$ inding, operating point Unom, Dnom

$\neg$ - Additional loss factor for secondary w inding, operating point Umin, Dmax

Fig. 8. Harmonic-loss factors for primary and secondary windings in case studies $A, B$ and $C$, respectively

That phenomenon can be explained by the following facts. The optimal transformer design rule of the copper and core loss equalization will not work for middlefrequency $(500 \ldots 2000 \mathrm{~Hz})$ high-power transformers, because the copper losses are dominating. They are usually more than $90 \%$ from the total losses of the transformer. Copper losses can approximately be expressed as follows:

$$
P_{\text {copper }}=I_{p r, r m s}^{2} \cdot R_{p r} \cdot F_{A L 1}+I_{\mathrm{sec}, r m s}^{2} \cdot R_{\mathrm{sec}} \cdot F_{A L 2},
$$

where $R_{p r}$ and $R_{s e c}$ are the resistances of the winding materials, $F_{A L 1}$ and $F_{A L 2}$ are the additional loss factors taking into account the rise of AC resistance compared to the DC resistance in the primary and secondary windings. As seen from Fig. 8, the harmonic loss factors are overcoming the rise of THD if the converter operates under high duty cycle and low voltage values (curve for the operating point $U_{\min }, D_{\max }$ in Fig. 8). As a result, the isolation transformers designed for the higher maximal duty cycle value demonstrate higher efficiency at any operational voltage and duty cycle (Fig. 9).

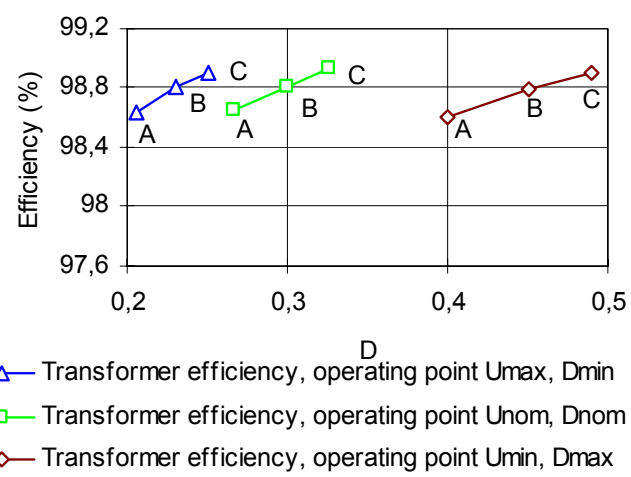

Fig. 9. Transformer efficiency in case studies $A, B$ and $C$, respectively

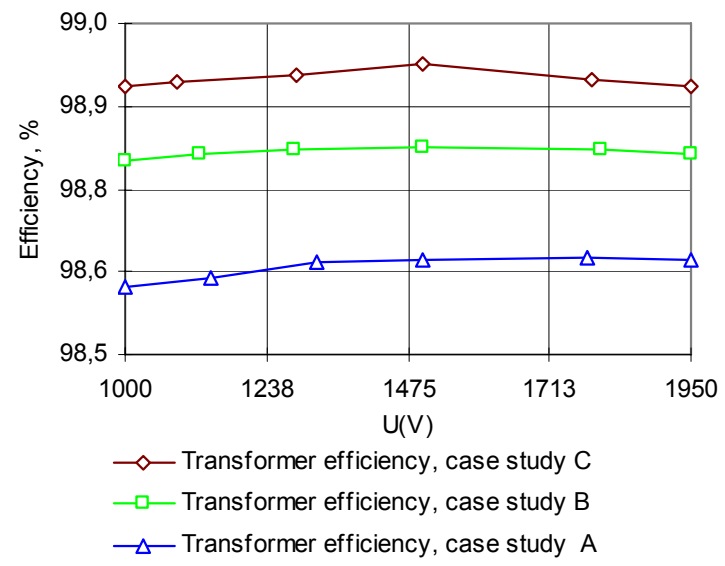

Fig. 10. Comparison of the efficiency of different isolation transformer designs for the same operating voltage range

Fig. 10 shows the comparison of the efficiency of the discussed isolation transformer designs estimated for the whole primary voltage range. The transformer designed with the highest maximal duty cycle (case study $C$ ) features about $0.3 \%$ efficiency rise compared to the conventional one (case study $A$ ). In the case of other transformer designs operating at higher temperatures, the energy efficiency improvement was of $1 \ldots 2 \%$, resulting in $0.5 \ldots 1 \mathrm{~kW}$ less power dissipation of the $50 \mathrm{kVA}$ isolation transformer. If the isolation transformer was 
designed with very low losses, e.g. efficiency was near $99.5 \%$, then the impact of proper selection of the nominal duty cycle on the transformer efficiency was negligible (reduction of losses was less than $15 \mathrm{~W}$ ).

\section{Conclusions}

In this paper, efficiency improvements of the highvoltage isolated $\mathrm{DC} / \mathrm{DC}$ converter by means of the improved selection of the variation range of the duty cycle of the inverter switch are discussed. A new extended approach of the inverter duty cycle selection is proposed. To verify the proposals, the efficiency of the inverter and isolation transformer was estimated and compared for three different duty cycle variation ranges.

It was found that the new method provides an efficiency rise of the high-voltage half-bridge isolated $\mathrm{DC} / \mathrm{DC}$ converter. In the case of the investigated rolling stock auxiliary power supply with the rated power of $50 \mathrm{~kW}$ even moderate efficiency improvement in $1 \%$ will be followed by the $0.5 \mathrm{~kW} \ldots 1 \mathrm{~kW}$ smaller heat dissipation, thus resulting in a reduced cooling effort and, therefore, higher power density of the designed converter.

\section{Acknowledgement}

Authors thank Estonian Science Foundation (Grant No. 7425 "Research of Dynamic Performance of HighVoltage IGBTs" and Grant No. 8020 "Research of Advanced Control and Diagnostics Systems for the HighPower IGBT Converters") for financial support of this study.

\section{References}

[1] Speisespannugen von Bahnnetzen, Deutsche Fassung EN50163:1995 (1996).

[2] D. Vinnikov, Research, Design and Implementation of Auxiliary Power Supplies for the Light Rail Vehicles, Ph.D. dissertation, TUT press (2005).

[3] T. Jalakas; D. Vinnikov and J. Laugis, "Development of $50-\mathrm{kW}$ Isolated DC/DC Converter with HighVoltage IGBTs", in Proc. CPE 2007, pp. 1-6.

[4] A.I. Pressmann, Switching Power Supply Design, Mc Graw Hill (1991).

[6] Lloyd H. Dixon, Magnetics Design for switching Power Supplies, Section 4: Power Transformer Design, Texas Instruments (2001).

[5] Zhang Xi, Deadtime calculation for IGBT modules, Infineon Technologies AG (2008).

[7] T. Jalakas; D. Vinnikov and J. Laugis, "Interlock Delay Time Minimization and its Impact on the High-Voltage Half-Bridge DC/DC Converter" (unpublished). 